\title{
Sildenafil improved sexual function in erectile dysfunction
}

\author{
Goldstein I, Lue TF, Padma-Nathan H, et al, for the Sildenafil Study Group. Oral sildenafil in the treatment of erectile \\ dysfunction. N Engl J Med 1998 May 14;338:1397-404.
}

\section{Question}

In men with erectile dysfunction, is sildenafil (Viagra) effective in improving erectile function and increasing the rate of successful attempts at sexual intercourse?

\section{Design}

2 randomised, double blind, placebo controlled trials with 24 weeks follow up for the dose response study and 12 weeks follow up for the dose escalation study.

\section{Setting}

37 centres in the US.

\section{Patients}

861 men (mean age 58 y) who had erectile dysfunction lasting $\geqslant 6$ months and were in a stable relationship with a female partner for $\geqslant 6$ months. Exclusion criteria were penile anatomical defects, another sexual disorder, spinal cord injury, major psychiatric disorder not well controlled with treatment, poorly controlled diabetes mellitus, peptic ulcer disease, history of alcohol or substance abuse, major systemic abnormalities, recent stroke or myocardial infarction, or receipt of nitrate therapy. $87 \%$ of men completed the dose response study and $93 \%$ completed the dose escalation study.

\section{Intervention}

Dose response study: men were allocated to placebo $(\mathrm{n}=216)$ or to 25,50 , or $100 \mathrm{mg}$ of sildenafil $(\mathrm{n}=316)$. Dose escalation study: men were allocated to placebo $(\mathrm{n}=166)$ or to $50 \mathrm{mg}$ of sildenafil $(n=163)$; the dose could be doubled or reduced by $50 \%$ at each follow up visit.

\section{Main outcome measures}

Mean response scores to questions on achieving penetration and maintaining erection (questions 3 and 4 of the International Index of Erectile Function [IIEF]); response scores on IIEF domains for erectile function, orgasmic function, sexual desire, intercourse sat- isfaction, and overall satisfaction; and response to a global efficacy question: did the treatment improve your erections?

\begin{abstract}
Main results
Analysis was by intention to treat. In the dose response study, the per cent increases from baseline on response scores for achieving penetration were $60 \%, 84 \%$, and $100 \%$ in patients who received 25, 50, and $100 \mathrm{mg}$, respectively, compared with $5 \%$ for placebo $(\mathrm{p}<0.001)$ and for maintaining erection were $121 \%$, $133 \%$ and $130 \%$, respectively, compared with $24 \%$ for placebo $(\mathrm{p}<0.001)$. In the dose escalation study, the per cent increases from baseline for achieving penetration and maintaining an erection with sildenafil were $95 \%$ and $140 \%$, respectively, compared with $10 \%$ and $13 \%$, respectively with placebo $(p<0.001)$. Mean scores for erectile function domain increased with increasing doses of sildenafil in the dose response study $(\mathrm{p}<0.001)$ and were higher than those for placebo in the dose escalation study $(\mathrm{p}<0.001)$. In response to the global efficacy question, improved erections were reported by $56 \%, 77 \%$, and $84 \%$ of patients who received 25,50 , and $100 \mathrm{mg}$ of sildenafil compared with $25 \%$ of patients who received placebo $(p<0.001)$ in the dose response study; the proportions in the dose escalation study were $74 \%$ for sildenafil and $19 \%$ for placebo $(\mathrm{p}<0.001)$. Adverse effects associated with sildenafil were mild and included headache, flushing, dyspepsia, and transient visual disturbances.
\end{abstract}

\section{Conclusion}

In men with erectile dysfunction, sildenafil improved erectile function, increased the rate of successful attempts at sexual intercourse, and was well tolerated.

Source of funding: Pfizer.

For correspondence: Dr I Goldstein, Department of Urology, Boston University Medical Center, 720 Harrison Avenue, P (606), Boston, MA 02118, USA. Fax +1 6176388487.

Abstract also published in ACP Journal Club.

\section{Commentary}

The media hype that accompanied the launching of sildenafil for the treatment of erectile dysfunction may be unprecedented and may obscure the true clinical value of the drug for some time.

The study by Goldstein et al presents convincing evidence of the therapeutic efficacy and lack of serious side effects of sildenafil. It is undoubtedly a drug of considerable theoretical and clinical interest and represents a fundamentally new and different approach to the pharmacotherapy of this common sexual problem. The authors, however, in considering alternative methods of therapy, ignore psychological treatment. Not only is sex therapy effective in a proportion of cases, but psychological aspects of an intraindividual or interpersonal kind are commonly involved even when organic fac- tors are important, and appropriate help should be available when necessary.

This study also gives the impression that the drug is effective whatever the cause of the erectile problem or the age of the patient. This is difficult to believe. Although the cyclic guanosine monophosphate step in the sequence between nitrous oxide release and smooth muscle relaxation which is prolonged by the drug may be of fundamental importance, there are many other points in the system where pathology may interfere. More studies are needed in which predictors of therapeutic response are examined in relation to specific aetiologies, both organic and psychogenic. However, because of its low level of side effects (and provided that specific contraindications such as concurrent use of nitrates are avoided) sildenafil can be regarded as the first line approach for erectile dysfunction. There may be many men, with either organic or psychogenic causation, who respond adequately to the drug alone. In other cases, psychological help in addition to or instead of sildenafil should be considered. In those patients in whom sildenafil is effective, the extent to which supply of this expensive drug should be covered by healthcare plans will be one of the more interesting debates in healthcare policy. It is not a trivial issue.

John Bancroft, MD

Kinsey Institute, Indiana University Bloomington, Indiana, USA 1 Hawton K, Catalan J, Fagg J. Arch Sex Behav
1992;21:161-75. 